\title{
Lithoclast $^{\circledR}$ Master in Intracorporeal Lithotripsy during Percutaneous Nephrolithotomy : Our Experience
}

\author{
Lt Col RS Rai*, Surg Capt KSK Patrulu+, R Rai", E Gupta**, Brig A Kayastha, sm ${ }^{++}$, Col S Sawhney ${ }^{\# \#}$
}

\begin{abstract}
Background: This study was carried out to compare the efficacy of Lithoclast ${ }^{\circledR}$ Master with pneumolithotriptor during percutaneous nephrolithotomy (PNL) in the treatment of renal staghorn calculi.

Methods: In this prospective study, 60 patients suffering from partial or complete staghorn renal stones were included. Patients were divided randomly in two groups : Groups I and II and underwent PNL for removal of stones. In Group I patients, standard pneumolithotriptor and in Group II, Lithoclast ${ }^{\circledR}$ Master was used for stone fragmentation. The patients were evaluated for rate of fragmentation/clearance, presence of residual fragments by KUB radiograph/ultrasound. Result was analyzed by Chi-square test. Result: The rate of fragmentation using Swiss Lithoclast ${ }^{\circledR}$ Master was more effective and quicker in comparison to standard pneumolithotriptor. The average time taken for fragmentation and clearance in Group I using pneumolithotriptor was 65 minutes, whereas it was 58 minutes using Lithoclast ${ }^{\circledR}$ Master, which was statistically significant ( $\left.p<0.01\right)$. Only 4\% patients had significant residual fragments $(>4 \mathrm{~mm})$ in Group II and $16(53 \%)$ patients in Group I, which was significant $(\mathrm{p}<0.01)$. The complications in both the modalities were insignificant; one $(1.33 \%)$ patient had bleeding and three $(10 \%)$ patients had urine leak in Group I; whereas three $(\mathbf{1 0} \%)$ patients had bleeding and five $(\mathbf{1 6 . 7 \% )}$ urine leak in Group II.

Conclusion: Lithoclast ${ }^{\circledR}$ Master is an effective intracorporeal lithotripter during percutaneous nephrolithotomy in the treatment of renal staghorn calculi for stone fragmentation/clearance with minimal residual fragments and complications.
\end{abstract}

MJAFI 2008; 64 : 232-233

Key Words : Staghorn calculus; Percutaneous nephrolithotomy; Lithoclast; Ultrasonic lithotripsy; Pneumatic lithotripsy

\section{Introduction}

Staghorn calculi typically, they fill the renal pelvis and Obranch into several or all of the calyces. These calculi are mostly composed of mixtures of magnesium ammonium phosphate (struvite) and/or calcium carbonate apatite [1]. Over a period of time, an untreated staghorn calculus is likely to destroy the kidney and/or cause life threatening sepsis $[2,3]$. Complete removal of the stone is the end point of therapy in order to eradicate infection, relieve obstruction, prevent further stone growth and preserve renal function [4,5]. As per the American Urological Association (AUA) Guidelines, all newly diagnosed patients of staghorn calculi should be actively treated by percutaneous nephrolithotomy (PNL) based on superior outcomes and low morbidity [4]. The most common energy source for fragmentation is either compressed air (pneumolithotripsy), ultrasound (ultrasonolithotripsy) or combination of compressed air and ultrasound. The aim is to leave behind no significant residual fragments to avoid re-growth of stones, obstruction and recurrent urinary tract infection $[6,7]$.
We compared the efficacy of the Lithoclast ${ }^{\mathbb{B}}$ Master, (which combines pneumolithotriptor and ultrasonic device) with standard pneumolithotriptor in terms of rate of stone fragmentation/clearance, significant residual fragments $(>4 \mathrm{~mm})$ and any complications during PNL in the treatment of renal staghorn calculi.

\section{Material and Methods}

This prospective study was carried out at this hospital from November 2005 to October 2006. Sixty patients suffering from partial or complete staghorn renal stones were included in this study. Patients suffering from calculus disease with renal compromise, bleeding diathesis, congenital renal anomalies, solitary functioning kidney and morbid obesity were excluded. The volumes of the stones were calculated by average of volumes assessed by plain KUB radiograph and ultrasonography. Patients were divided randomly in two groups of 30 patients each. They underwent PNL under spinal anaesthesia. In Group I patients, pneumolithotriptor with suction and in Group II, Lithoclast ${ }^{\mathbb{B}}$ Master (using ultrasonic and pneumolithotriptor simultaneously) was used. Follow up for rate of fragmentation/clearance, residual fragments and complications was done. The results were analyzed by chi-square test.

"Classified Specialist (Surgery \& Urology), Command Hospital (Western Command), Chandimandir-134107 (Haryana). ${ }^{+}$Classified Specialist (Surgery \& Urology), "\#Senior Advisor (Anaesthesiology), Command Hospital (Northern Command), C/o 56 APO. \#,*Internee Medical Officer, Government Medical College \& Hospital, Chandigarh. ${ }^{++}$DDMS, HQ 11 Corps, Jalandhar (Punjab). 


\section{Results}

There were 60 patients comprising of 38 males and 22 females in the age groups of 11-70 years, commonest being 31- 40 years. In Group I, out of 30 patients, 20 had partial staghorn stones and 10 had complete staghorn stones. The smallest stone was $26 \times 19 \times 19 \mathrm{~mm}$ (volume $9386 \mathrm{~mm}^{3}$ ) and the largest $60 \times 55 \times 55 \mathrm{~mm}$ (volume $181500 \mathrm{~mm}^{3}$ ). The average time taken for fragmentation by pneumolithotriptor and retrieval of fragments was 64 minutes ( range 44-124 minutes). In Group II, 19 patients had partial staghorn stones and 11 had complete staghorn stones. The smallest stone was $20 \times 19 \times 29 \mathrm{~mm}$ (volume $11020 \mathrm{~mm}^{3}$ ) and the largest $75 \times 57 \times 72 \mathrm{~mm}\left(307800 \mathrm{~mm}^{3}\right)$. The average time taken for the fragmentation and clearance by Lithoclast ${ }^{\circledR}$ Master was 58 minutes ( range 40 - 94 minutes).

It was observed that one $(1.33 \%)$ patient in Group I and three $(10 \%)$ patients in Group II had bleeding, which did not require any transfusion. In one patient the procedure was abandoned because of bleeding at the time of puncture and tract dilatation. Three (10\%) patients in Group I and five( $16.7 \%$ ) in Group II had urine leak for more than 72 hours, which subsided with conservative measures. The average time taken for fragmentation and clearance in Group I (average volume of calculi $25367 \mathrm{~mm}^{3}$ ) using pneumolithotriptor was 65 minutes, whereas, it was 58 minutes in Group II using Lithoclast ${ }^{\circledR}$ Master in spite of having larger volume of calculi (average volume $44632 \mathrm{~mm}^{3}$ ), which was statistically significant $(\mathrm{p}<0.01)$. Four $(13 \%)$ patients in Group II had significant residual fragments against 16 (53\%) in Group I, which was statistically significant $(\mathrm{p}<0.01)$.

\section{Discussion}

Percutaneous nephrolithotomy can be used for most stones but shock wave lithotripsy (SWL) is still used in the majority having smaller renal stones. The current evidence suggests that patients with staghorn calculi are best managed with PNL based therapy, either as single technique or in combination with SWL to achieve maximal clearance. If not treated, these staghorn stones can serve as a source of persistent morbidity, such as recurrent urinary tract infection, pyelonephritis and sepsis. In fact the combination of stones, obstruction and recurrent infection can result in the development of xanthogranulomatous pyelonephritis [3,8-10]. Among all the modalities available for the treatment of these stones, the stone-free rate following treatment is highest (78\%) for PNL. On an average, PNL requires 1.9 total procedures while combination therapy and SWL require 3.3 and 3.6 total procedures respectively [4].

Initial debulking (stone fragmentation) traditionally relied on ultrasonic energy. Similarly pneumatic lithotripsy provides a rapid, efficient means of fragmenting stones. Recently a combination device has been developed that incorporates ultrasonic and pneumatic lithotripsy in a single instrument in which the two modalities are used simultaneously or alone to increase the speed and versatility of rigid nephroscopy [11]. Swiss Lithoclast ${ }^{\circledR}$ Master (EMS) uses both these modalities either simultaneously or alone. Hofmann et al [12] achieved stone-free rate was $66 \%$ after first PNL and after second look, the stone-free rate of $80 \%$ with Lithoclast ${ }^{\mathbb{B}}$ Master. The stone were composed of calcium oxalate monohydrate (COM) in $13 \%$, COM with uric acid in $35 \%$, apatite in $20 \%$ and cystine in $11 \%$ cases.

We concluded that Lithoclast ${ }^{\circledR}$ Master is an effective lithotripter for intracorporeal lithotripsy which leaves minimal residual fragments with minimal complications.

\section{Conflicts of Interest \\ None identified}

\section{Intellectual Contribution of Authors}

Study Concept : Lt Col RS Rai

Drafting \& Manuscript Revision : Lt Col RS Rai, R Rai, E Gupta Study Supervision : Lt Col RS Rai, Brig A Kayastha, SM, Surg Capt KSK Partulu, Col S Sawhney

\section{References}

1. Bruce RR, Griffith DP. Retrospective follow-up patients with struvite calculi. In: Smith LH, Robertson WGL, Finlayson B, editors. Urolithiasis Clinical and Basic Research. New York: Plenum Press 1981; 191.

2. Rous SN, Turner WR. Retrospective study of 95 patients with staghorn calculus disease. J Urol 1977; 118: 902.

3. Koga S, Arakaki Y, Matsuoka M, Ohyama C. Staghorn calculilong term results of management. Br J Urol 1991; 68: 122.

4. Glenn M, Preminger GM, Assimos DG, Lingman JE, Nakada SY, Pearle M S, et al. AUA guidelines on management of staghorn calculi: Diagnosis and treatment recommendations. J Urol 2000; 173: 1991-01.

5. Blandy JP, Singh M. The case for a more aggressive approach to staghorn stones. J Urol 1976; 115: 505-6.

6. Streem SB, Geisinger MA, Risius B, Zelch MG, Seigel SW. Endourologic sandwich therapy for extensive staghorn calculi. J Urol 1997; 158: 342.

7. Bech EM, Riehle A Jr. The fate of residual fragments after extracorporeal shockwave lithotripsy monotherapy of infective stones. J Urol 1991; 145: 6.

8. Vargas AD, Bragin SD, Mendez R. Staghorn calculus: its clinical presentation, complication and management. J Urol 1982; 127 : 860 .

9. Srinivasan A, Mowad JJ. Pyelocutaneous fistula after SWL of xanthogranulomatous pyelonephritis kidney: case report. J Endourol 1998; 2: 13-5.

10. Alifano M, Venissac N, Chevalier D, Mouroux J. Nephrobronchial fistula secondary to xanthogranulomatous pyelonephritis. Ann Thorac Surg 1999; 68:1836-8.

11. Pietrow PK, Auge BK, Zhong P, Preminger GM. Clinical efficacy of a combination pneumatic and ultrasonic lithotrite. Randomized controlled trial. J Urol 2003; 169: 1247.

12. Hofmann R, Olbert P, Weber J, Wille S, Varga Z. Clinical experience with a new ultrasonic and Lithoclas $\mathrm{t}^{\mathbb{B}}$ combination for percutaneous lithoplaxy. BJU International 2002; 90: 16-9. 